\title{
Psycho-Organizational Factors in Employee Acceptance of Organizational Change in the Federal Civil Service
}

\author{
Catherine Chovwen \\ Department of Psychology \\ University of Ibadan \\ chovwenc@yahoo.com
}

DOI: $10.36108 / \mathrm{NJSA} / 4102 / 12(0280)$

\begin{abstract}
Although change is constant, and thus, should be expected, studies have shown that individuals and groups resist change in most situations. This study particularly focused on factors that could promote acceptance of change among 257 management and nonmanagement staff in a bureaucratic public sector where 'things are done as usual'. Specific variables of interest include personality and sense of competence, organizational support and culture as independent variables and acceptance of change as dependent variables. The results showed that openness to change and extraversion were positively related to acceptance; females were more favorably disposed to change than males and male and female management staff scored high on acceptance of change than non-management members. The results enhanced understanding of personality traits and organizational dynamics that propel individuals to accept change, reduce resistance as well as promote adaptation to change.
\end{abstract}

Keywords: organizational change, personality, competence, organizational culture, acceptance

\section{Introduction}

Changes have been taking place since the emergence of the Civil Service in Nigeria and many of these involve structures, operations, processes and procedures in the delivery of services (Olaopa, 2009). Organizational change connotes effort or series of efforts to modify an organization's structure, goals, technology or work task (Carnall, 1986), brought about by both internal and external factors. The changes often alter key organizational variables with consequence on work-related behaviours, resulting in changes in variety of organizational outcomes. Therefore, organizational change can be looked at as a critical life event which has potential to evoke stress reaction and other negative consequences on the employee. In this regard, employees may be confronted with a unique set of work-place stressors resulting from a changing work environment (Jimmieson et. al. 2004). It is often assumed that employees would accept a variety of changes and be willing to adapt them since change is inevitable, but the literature has shown that change can be resisted (Huse, 1980).

Studies on organizational change have identified lack of trust (Gardner, Dunham, Cummings and Pierce, 1987), frozen attitudes (Schein, 1979), nonparticipation (Coch and French, 1948) and fear of the unknown (Huse, 1980) as the causes of the display of resistance to organizational change. It has been 
argued that employees are likely to experience uncertainty over many different facets of a changing work environment and as a result several reactions trail such changes. Specifically, Shaw, Fields, Thacker and Fisher (1993) posited that among other factors, role stress is likely to result from uncertainty associated with organizational change. Role conflict may be particularly prevalent during organizational change due to anticipation about the unknown and possible contradictory expectations of the new organization which may be in direct contrast to the expectations of the old organization. Similarly, role ambiguity may occur when the expectations applicable to the old organization have not been replaced with clear expectations set by the new organization. Employees may also experience role overload when too many tasks assigned in a given time period or when new job duties go beyond their knowledge, skills and abilities.

In addition to experiencing uncertainty over the nature of present and future job responsibilities, Callan (1993) observed that employees may perceive organizational change as a major source of threat to their personal career paths and financial well-being. For Greenhalgh and Rosenblatt (1984) employees may experience the loss of many intangible features associated with their work environment, such as power and prestige and a sense of community at work. To mitigate the effect of change on employees and ensure success, Judson (1991) identified a variety of tactics that managers can employ to minimize resistance to change, including threats and compulsion, criticism, persuasion, inducements and rewards, compromises and bargaining, guarantee against personal loss (e.g. offering job security or retraining to employees), psychological support, employee participation, ceremonies and other efforts to build loyalty, recognition of the appropriateness and legitimacy of past practices, and gradual and flexible implementation of change.

Researchers (Armenakis, Harris and Field, 1999; Bingham and Wise, 1996 and Kotter, 1995; 1996) have proposed models and frameworks of change based on Lewin's (1947) steps and phases of change. These studies describe the process of implementing change within organizations and points to factors contributing to success. A consensus amongst the researchers is that change leaders and change participants should pay special attention to some factors such as ensuring the need for the change (Kotter, 1995; Laurent, 2003; Nadler and Nadler, 1998), starting with crafting a vision for it and employing persuasive communication for the support of all employees and external stakeholders (Young, 2001), providing a course of action or strategy for implementing change, building internal support for change and overcome resistance through widespread participation in the change process particularly for career civil servants and pursuing comprehensive change through integrative, comprehensive approach to change that achieves subsystem congruence.

Good as the models and frameworks are, many of them downplay the significance of psycho-organizational factors predicting employees' acceptance of change. This has not been adequately explored in previous studies, although 
some related personality factors, organizational support and job position with the acceptance of change. For example, Vakola et. al. (2004) reported that attitude toward organizational change is positively related to extraversion (characterized by high sociability, external stimulation), agreeableness (soft hearted compliant, good nature that avoids tension and disagreement), conscientiousness (self discipline, ambition and competence), and openness to experience (openness to new ideas and suggestion and tolerance) implying acceptance but negatively related to neuroticism (worry, nervousness and anxiety) indicating resistance. More specifically, McCrae and Costa (1986) indicated a positive relationship between openness to change and utilization of effective coping mechanisms in order to deal with stressful events in life.

Other important variables worthy of consideration during organizational change process include self competence. Ashford (1988) argued that changerelated self-competence is an employee's perceived ability to function well on the job, despite the demands of a changing work environment. Employees who doubt their ability to respond to the demands of a specific organizational change event are likely to focus attention on their feelings of incompetence, which will be accompanied by feelings of psychological distress, and a failure to deal with the situation. In contrast, employees who have high levels of change-related efficacy are unlikely to be distressed by feelings of inadequacy and, for this reason, are expected to persist in their efforts to manage the organizational change process. A review conducted by Terry and Callan (2000) indicated that employees who appraise the impending organizational change as being amenable to personal control and believe that they have the ability to cope with the demands of the situation are more likely to experience better adjustment to a changing work environment. This is an indication that employees' personality characteristics play important roles in the psychological transition that occurs during organizational change.

It has also been argued that for employees to accept organizational change there must be what is called perceived Organizational support. Perceived organizational support is organization's treatment of its employees and this provides a means of interpreting the organization's motives. As noted by Johlke, Stamper and Shoemaker (2001), organisations are increasingly using discretionary, intangible investments in employees such as training, for their impact on employee performance, satisfaction and commitment with a view to promote support for employees. Opportunities for employee development are likely to be interpreted as action indicating that the organization cares for its employees (Babakus, Craven, Johnston and Moncrief, 1996). Beyond this, perceived organizational support could also be reflected in feedback, praise, encouragement, recognition employees receive from peers and supervisors. Consistent with this, favorable opportunities for rewards and other facilities provided by organizations to cushion negative effects of change may convey organization's positive valuation of employees' contributions. Armenakis et. al. 
(1993) indicated that beliefs, perceptions and attitudes are critical in successful change. Unless the majority of staff perceives that the organization develops supportive organizational mechanisms to change, such as top management commitment, allocation of resources, rewards, training, participation in the planning and implementation, etc. (McHugh, 1993) change will be a stressful experience and may be resisted by employees. Therefore, it would be beneficial to investigate the extent to which perceptions of organizational support in the Federal Civil Service influence employees' acceptance of change.

In addition to the above view, it is assumed that organizational culture may play a significant role in acceptance of organizational change. Organizational culture is the identity of the organization made up of members shared meanings of values and how these values are rewarded and reinforced to mold member's behavior. Pettigrew (1979) viewed organizational culture as the patterns of beliefs, symbols, rituals, and values, assumptions that evolve and are shared by the members of the organization. Schein (1992) defined organizational culture as a deep level basic assumptions and beliefs that are shared by members of the organization and are believed to be real. He focused on the aspect that culture is learned, shared and comprise of tacit assumptions on which people base their daily behavior. Culture thus, becomes a paradigm, a reality, and affects employees' decisions, actions and behaviours. When change is properly molded and engrained as part of the culture of an organization, it is taken as acceptable while amenability and its acceptance become less resisted.

The civil service has its tradition edged in the Classical Theories of Management exemplified by the works of Max Weber who popularized the concept of bureaucracy. The concept has its origin in the French word bureau office, and the Greek word kratos which connotes strength, power, dominion, sovereignty, rule and mastery (Olaopa, 2009). Weber's bureaucracy is anchored on principles such as formal hierarchical structure, management by rules, organization by functional specialty, impersonal relationship - that is equal treatment with employment and promotion based on technical competence. He also identified precision, continuity, discipline, strictness and reliability as features of bureaucracy. It should be noted though that Weber's reference is to an 'ideal-type' bureaucracy, which is never realizable (Mullins, 2010).

Interestingly the bureaucratic nature of most government establishments depicts images of slothfulness, inefficiency and status quo mindset, a setting that may work contrary to change. During these first generation reforms in Nigeria, it appeared that too much attention was given to financial measures and the reduction of the size of the civil service, while too little attention was given to questions regarding the role of the state and the need for a (qualitative) service delivery. The second generation of civil service reforms, therefore, was focused on reducing the costs of the civil service as well as increasing its quality. The main objectives were professionalization of staff, transparent and performance -related personnel policies and the improvement of the service 
delivery (Osaghae, 1995). In a bureaucratic organizational structure, authority is generally centered at the top, and information flows mainly from the top down. This usually encourages an organizational culture focused on rules and standards, where operational processes are rigidly controlled with routine methodologies and close supervision. Mullins (2010) observed that the overemphasis on procedure, rules and regulation could lead to officious bureaucratic behaviours while the impersonal attribute could engender stereotyped behaviour and lack of responsiveness to the needs of the employees.

Contemporary change program result from resulted in response to technological advancement and globalization, competitive pressures, demands for greater transparency and accountability, need for higher productivity and loss of trust in government institutions. Although, Lewin (1947) developed a programme of planned change and improved performance to guide change process, it has been observed that organizational change is not linear. Ashford (1988), Callan (1993) and Carnall (1986) all observed that the most frequent psychological state resulting from organizational change is uncertainty, thus, change may be resisted in traditional bureaucratic civil service setting due to the peculiarity round it as outlined above. Thus, at the heart of the success or failure of change process in the Civil Service is the change agents: the leadership expected to implement the changes. Holbeche (2006) points out that most theorists now agree that the key challenge of change lies in the highly political, intuitive and emotional process of leadership.

Change leaders at any level need to be able to understand the human elements at work in any change process, and to use judgments about the nature of leadership task required to give the change effort the best chance of success. Resistance to change is often understood from the management standpoint as a perceived behaviour of organization's members who refuse to accept an organizational change (Cheng \& Petrovic-Lazarevic, 2004; Coghlan, 1993). Obviously being viewed as adversarial and detrimental, resistance to change has gained a negative connotation (Waddell and Sohal, 1998) that allegedly confounded the problem of effecting change by promulgating a dichotomous thinking of labour versus management (Dent and Goldberg, 1999). An appreciation of resistance to change from a more pluralistic employee-centred perspective and its role in organizational change (Waddell and Sohal, 1998) has lead to the resistance to change interpretation from a psychological point of view (Conner, 1998), as a natural outcome of people's internal defence mechanism (Bovey and Hede, 2001), or background conversations among employees that constitute the constructed reality (Ford, Ford \& McNamara, 2002).

Paterson and Hartel (2000) interpreted resistance to change as a people's cognition and affect or the perceived organizational justice done, while Rousseau (1989), McLean Parks and Kidder (1994) find it significantly related 
with the violation of the employment psychological contract. Olufemi (2009) reported that employees in manufacturing organization in Nigeria are likely to embrace change but will resist it only if it raises certain legitimate concerns among them. Since change is widely accepted as almost always top-down and induced by the management, those being managed would also almost always resist change, imposing an imperative for managers to overcome the resistance before it could bring the change forward.

Managers being stimulated to increase organizational effectiveness are initiating change with the expectation to motivate others to do more than they originally intended, and often even more than they thought possible (Cheng, Petrovic-Lazarevic, 2005; Yukl, 1998). Employees may go further by blaming management for not acting in their best interest and consequently undertake jobs and tasks with a poor attitude. While it is recognized that change initiatives must deliver sufficient benefits and operate in line with well thought out plans, the process must have the participation and acceptance by the employees (Evans et. al., 2002). Olufemi (2009) reported that for these plans to be successful, they require the joint effort and interpersonal trust of all employees from the top to the bottom of the organizational hierarchy.

Literature is not consistent on the relationship between attitude to change and gender. Iverson (1996) did not find any relationship between gender and attitudes toward change while Cordery et. al. (1991) reported that men were more resistant to change than women when they perceived they are gaining skills in traditional women's job e.g. typing. Vakola and Nikolau (2006) found females scored higher than males on attitudes towards organizational change, suggesting that males tend to be more reluctant than females towards organizational change. Furthermore, Vakola, Tsaousis and Nikolaou (2003) found no gender difference regarding attitudes toward organizational change. Regarding personal variables, they also reported significant effect of educational attainment on attitude toward change. Specifically, research among students revealed that university students expressed less positive attitude from those with further education and post graduate degree holders. Also, in this study, tenure was not related to organizational change.

Consequent on the foregoing, this study sets out to explore psychological constructs: self-competence and personality; and organizational factors: perceived organizational support and organizational culture that may contribute the acceptance of change among Federal Civil Service employees. The following research hypotheses will be tested in the study:

1. Personality factors, self competence, organizational support and culture exert significant positive influence on acceptance of change among male and female employees in the Federal Civil Service?

2. There is a significant difference between male management and non management employees on acceptance of organizational change.

3. There is a significant difference between female management and non management employees on acceptance of organizational change? 
4. Male federal employee reports higher acceptance of change than female federal employees.

5. Socio-demographic factors significantly and positively predict acceptance of change among male and female employees in the Federal Civil Service?

\section{Methods}

Research participants and selection procedure

The study is a survey that involved two hundred and fifty seven employees of the federal civil service selected from four Ministries, Departments and Agencies (MDAs) namely: Federal Ministries of Industry, Trade and Investment, Water Resources, and Youth and the Bureau of Public Service Reforms. The researcher sampled these ministries through the use of simple random sampling technique while the employees' were selected using convenient sampling method.

Permission was sought from the various Ministerial Heads of the selected Ministries, Departments and Agencies in Federal Civil Service before the administration of questionnaires. 300 questionnaires were administered to the workers out of which 257 screened questionnaires were analyzed for the study.

\section{Measures}

\section{Self-Competence Scale (SLCS)}

Tafarodi and Swann Jnr. (1995) eight item Self-competence scale anchored on the five-point Likert scale, ranging from strongly agree to strongly disagree, was used in this study. The scale reliability is 0.85 while the reliability for the current study is 0.86 Cronbach's Alpha.

\section{Ten Items Personality Inventory (TIPI)}

The TIPI was developed and validated by Gosling, Rentfrow and Swann Jnr. (2003). The authors reported a reliability coefficient of 0.72 while the scale yielded a coefficient of .56. The scoring is based on the five point Likert format.

\section{Perceived Organizational Support Scale (POSS)}

Eisenberger, Huntington, Hutchison and Sowa (1986) developed the 16item Perceived Organizational Support Scale which was administered to measure the perceived organizational support. It has 0.93 reliability alpha coefficient and the current study recorded 0.69 Cronbach's alpha for the scale.

\section{Organizational Culture Survey (OCS)}

Organizational Culture Survey Scale was developed by Glaser, Zamanou and Hacker (1987). It is a 22 item scale that was administered with five Likert scale response that ranged from strongly agreed (5) to strongly disagreed (1). The 
reliability for the scale was 0.77 . In the current study, it yielded reliability coefficient of 0.77 .

\section{Acceptance of Change Scale (ACS)}

Acceptance of change scale was developed by Gagne, Zucherman and Koestner (2000). It is a nine item scale. The scale yielded a reliability coefficient of 0.71 , while in the current study the composite reliability alpha coefficient is 0.72 .

\section{Procedure}

The four Organizations included in this study were randomly selected from federal government establishment in the Federal Capital Territory, Abuja. The researcher explained the purpose of the study and how respondents were expected to respond to the various statements in the questionnaires. The workers were allowed to go home with the questionnaires so that they could take time to read, understand and carefully fill the necessary information. The administration of questionnaires took four weeks as retrieval was difficult due to distance in terms of location of one organization to the other as well as the unwillingness of the respondents in returning the questionnaires. Of 300 questionnaires administered, 257 copies $(86 \%)$ were eventually considered as usable data, 5 were invalidated as a result of inappropriate filling, while 38 could not be retrieved and were therefore, discarded.

\section{Results}

Demographic data on the participants are presented below: Participants' years of experience with the federal civil service ranged from one to 35 years. The frequency distribution of participants across different strata revealed the following: male participants were $153(59.5 \%)$ while females were 104 $(40.5 \%)$. The age distribution ranged between $30 \mathrm{yrs}$ and $51 \mathrm{yrs}$. Educational qualification distribution of participants showed that $61(23.7 \%)$ were holders of secondary school certificates, 121 (47.1\%) were holders of OND/NCE, First degree/BSc were $54(21.0 \%)$ and participants with higher degrees were 20 representing $(7.8 \%)$ of the 257 sample size. The frequency distribution of participants by work experience showed that $80(31.1 \%)$ had between $0-5$ years of experience; $89(34.6 \%)$ had between 6 - 10years experience, $62(24.1 \%)$ had between 11-15 years of experience while $26(10.1 \%)$ had above 16 years working experience. The frequency distribution by salary scale indicated that $171(66.5 \%)$ were between GL 01and 06, 59(23.0\%) were between GL07-14 and $27(10.5 \%)$ were between GL $15-17$ out of 280 respondents.

The first hypothesis predicted that personality factors, perceived organizational support, sense of competence and organizational culture will jointly and independently predict acceptance of change among male employees. The result is presented in Table 1. 
Table 1: Summary table of Multiple Regressions analysis showing the influence of personality factors, perceived organizational support, sense of competence and organizational culture on acceptance of change among male employees

\begin{tabular}{lccc}
\hline Variable & $\boldsymbol{\beta}$ & $\mathbf{t}$ & $\mathbf{P}$ \\
\hline Extraversion & .174 & 13.25 & $*$ \\
Agreeableness & .200 & 2.997 & $\mathrm{~ns}$ \\
Neuroticism & .104 & -1.457 & $\mathrm{~ns}$ \\
Openness & .266 & 2.367 & $*$ \\
Conscientiousness & .173 & 1.247 & $\mathrm{~ns}$ \\
Organizational support & .175 & 2.547 & $\mathrm{~ns}$ \\
Sense of competence & .142 & 6.606 & $*$ \\
Organizational culture & .261 & 1.063 & $\mathrm{~ns}$ \\
\hline
\end{tabular}

Significance level $*<.0 .5$

Results showed that personality factors, perceived organizational support, sense of competence and organizational culture jointly predicted acceptance of change among male employees in the Federal Civil Service $\left(\mathrm{R}=.599, \mathrm{R}^{2}\right.$ $=.359, \mathrm{~F}(8,144)=64.279, \mathrm{P}<.05)$. This implies that personality factors, perceived organizational support, sense of competence and organizational culture jointly accounted for about $35.9 \%$ variance in acceptance of change among male employees. However, only sense of competence, extraversion and openness to experience had significant independent prediction on acceptance of change among male employees.

Hypothesis 2 predicted that personality factors, perceived organizational support, sense of competence and organizational culture will jointly and independently predict acceptance of change among female employees. The result of the prediction is presented in Table 2.

Table 2: Summary table of Multiple Regressions analysis showing the influence of personality factors, perceived organizational support, sense of competence and organizational culture on acceptance of change among female employees

\begin{tabular}{lccc}
\hline Variable & $\boldsymbol{\beta}$ & $\mathbf{t}$ & $\mathbf{P}$ \\
\hline Extraversion & .250 & 10.215 & $*$ \\
Agreeableness & .063 & 3.210 & $*$ \\
Neuroticism & 114 & -1.241 & $\mathrm{~ns}$ \\
Openness & .237 & 2.971 & $*$ \\
Conscientiousness & .219 & 5.264 & $\mathrm{~ns}$ \\
Organizational support & .152 & 4.027 & $*$ \\
Sense of competence & .146 & 1.674 & $\mathrm{~ns}$ \\
Organizational culture & .350 & 1.917 & $\mathrm{~ns}$ \\
\hline Significance level & & &
\end{tabular}

Significance level $*<.0 .5$ 
Table 2 shows that personality factors, perceived organizational support, sense of competence and organizational culture jointly predicted acceptance of change among female employees in the Federal Civil Service $\left(\mathrm{R}=.642, \mathrm{R}^{2}\right.$ $=.412, \mathrm{~F}(8,95)=72.109, \mathrm{P}<.05)$. This implies that personality factors, perceived organizational support, sense of competence and organizational culture jointly accounted for about $41.2 \%$ variance in acceptance of change among female employees. However, only perceived organizational support, extraversion, agreeableness, openness to experience personality factors had significant independent influence on acceptance of change among female employees. It was equally predicted that male employees in the management cadre will report significantly higher acceptance of change than non management cadre male employees. The result is presented in Table 3.

Table 3: T-test Summary showing difference between management and non management cadres on acceptance of change among male employees

\begin{tabular}{|c|c|c|c|c|c|c|}
\hline Cadre & $\mathbf{N}$ & Mean & SD & df & $\mathbf{t}$ & p \\
\hline \multirow{2}{*}{ Management } & & 46 & 32.67 & & 5.95 & \\
\hline & & & & 151 & 6.312 & $<.05$ \\
\hline Non-management & 107 & 28.29 & 5.1 & & & \\
\hline
\end{tabular}

Sig level: $*<.05$

Result indicates that male employees who belong to the management cadre scored significantly higher on acceptance of change than non management male employees $\mathrm{t}(151)=6.312, \mathrm{P}<.05)$. Comparatively, it was predicted that female who belong to the management cadre will report significantly higher acceptance of change compare with non management female employees. The result is presented in Table 4.

Table 4: T-test Summary showing difference between management and non management cadres on acceptance of change among female employees

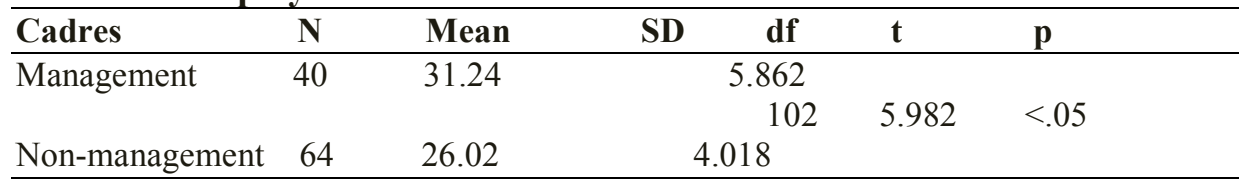

Sig level: ${ }^{*}<.05$

Table 4 result indicates that female employees who belong to the management cadre scored significantly scored higher on acceptance of change than nonmanagement female employees $(\mathrm{t}(102)=5.982, \mathrm{P}<.05)$. It was hypothesized that male civil servants will score significantly low on the measure of acceptance of change than their female counterparts among employees in the federal civil service. 
Table 5: T-test Summary table showing difference between males and females on acceptance of change

\begin{tabular}{lcccccccc}
\hline & Sex & N & Mean & SD & df & t & p \\
\hline \multirow{2}{*}{ Acceptance of change } & Male & 153 & 32.62 & 5.823 & & & \\
& & & & & 255 & -.791 & $<.01$ \\
\hline & Female & 104 & 33.24 & 6.335 & & & \\
\hline
\end{tabular}

Sig level: ${ }^{* *<.01}$

Result indicates that female civil servants scored higher on acceptance of change than their male counterparts at $\mathrm{t}(255)=-.791, \mathrm{P}<.01)$. Male civil servants had a mean score of (32.63); female civil servants had a mean score of (33.24). The fourth hypothesis predicted that age, educational qualification, job status, work experience and salary scale will jointly and independently predict acceptance of change among male employees. The result is presented in Table 6.

Table 6: Summary table of Multiple Regressions analysis showing the influence of age, educational qualification, job status, work experience and salary scale on acceptance of change among male employees

\begin{tabular}{lccc}
\hline Variable & $\boldsymbol{\beta}$ & $\mathbf{t}$ & Sig \\
\hline Age & .021 & 2.154 & $\mathrm{~ns}$ \\
Educ. qualification & -.062 & -1.004 & $\mathrm{~ns}$ \\
Job status & .157 & 1.329 & $\mathrm{~ns}$ \\
Work Exp. & -.120 & 1.152 & $\mathrm{~ns}$ \\
Salary & -.093 & -4.597 & $*$ \\
\hline
\end{tabular}

Sig level: $*<.05$

The above results revealed that age, educational qualification, job status, work experience and salary scale had no significant joint prediction on acceptance of change among male employees in the Federal Civil Service $\left(\mathrm{R}=.104, \mathrm{R}^{2}\right.$ $=.011, \mathrm{~F}(5,147)=1.514, \mathrm{P}>.05)$. However, only salary had significant independent influence on the acceptance of change among male employees in the Federal Civil Service $(\beta=.093, \mathrm{t}=-4.597, \mathrm{P}<.05)$.

The fifth hypothesis predicted that age, educational qualification, job status, work experience and salary scale will jointly and independently predict acceptance of change among female employees. The result is presented in table 7. 
Table 7: The influence of age, educational qualification, job status, work experience and salary scale on acceptance of change among female employees

\begin{tabular}{lcrc}
\hline Variable & $\boldsymbol{\beta}$ & $\mathbf{t}$ & $\mathbf{P}$ \\
\hline Age & .013 & 3.003 & $*$ \\
Educ. qualification & -.051 & -1.102 & $\mathrm{~ns}$ \\
Job status & .019 & 1.245 & $\mathrm{~ns}$ \\
Work Exp. & -.044 & -1.040 & $\mathrm{~ns}$ \\
Salary & -.053 & -.514 & $\mathrm{~ns}$ \\
\hline
\end{tabular}

Sig level: $*<.05$

The results in table 7 showed that age, educational qualification, job status, work experience and salary scale jointly predicted acceptance of change among employees in the Federal Civil Service $\left(\mathrm{R}=.177, \mathrm{R}^{2}=.031, \mathrm{~F}(5,98)=2.165\right.$, $\mathrm{P}<.05$ ). This implies that age, educational qualification, job status, work experience and salary scale jointly accounted for about $0.31 \%$ variance in acceptance of change among female employees. However, only age had significant independent influence on the acceptance of change among female employees in the Federal Civil Service $(\beta=.013, \mathrm{t}=3.003, \mathrm{P}<.05)$. This implies that age, educational qualification, job status, work experience and salary scale jointly predicted acceptance of change among female employees.

\section{Discussion}

The hypothesis that predicted the joint interaction among all variables on acceptance of change among federal civil service male employees highly significant, as personality factors, perceived organizational support, sense of competence and organizational culture combined to account for 35.9 per cent of the variance in acceptance of change. In line with this, some researchers advocated that for employees to accept organizational change, it was necessary to approach such an adventure through a combination of an integrative and comprehensive involvement of factors other than organizational rules and laws (Burke, 2002; Young, 2001). For example, Adeniji et. al. (2013) found that in the banking industry, there exists significant positive relationship between integration of human resources and employees' commitment. These results suggest that a strong commitment can be expected when employees are effectively integrated thereby aiding successful change management. This suggestion gave rise to this prediction in the present study.

Further analysis of the result to confirm the independent contribution of the factors considered in this study revealed that only extraversion and openness, among the personality factors and sense of competence independently contributed significantly to acceptance of organizational change especially among male employees. In line with Ashford's (1988) argument that change related self competence may influence such a move in the organization, there is the possibility in the present study that males see themselves as having the necessary competence to confront whatever form of change that might be 
coming up in the work environment. Therefore, they would be able to control the challenges coming from such a change (Terry and Callan, 2000). Openness (indicates that an individual is receptive to new ideas and suggestion and thus, may be tolerant to change) extraversion (which connotes personality characterized by excitability, sociability and external stimulation) and competence underscore the significant linkage between these and other organizational variables and the importance of personality characteristics in organizational analysis and outcomes. The display of these characteristics will promote high acceptance of change and such individuals could be used as change agents promoting positive attitudes from colleagues.

Since the issue of gender was involved in this study, a look at the above mentioned factors on the acceptance of change among females was considered necessary. As revealed in Table 2, there was equally a significant joint contribution (41.2\%) of the factors considered on acceptance of change among the female employees, still confirming what others have said and predicted in the literature on dispositional and contextual factors influencing acceptance of change. However, only extraversion, agreeableness, openness and organizational support independently influenced acceptance of change. For females, it seems their assumed compliant and soft hearted nature suggests that they are less likely to resist change. It could also mean that they expect management to be more considerate and provide the necessary support to cushion the negative effect of change, as the case may be, and promote acceptance. Supportive and positive work relationships were found to be helpful when individuals attempt to cope with organizational change (Shaw et. al., 1993). This reaction may also indicate the fear that they might be victims of the change which might lead to job loss, unlike the males who see competence as essential factor for adjustment. However, both were influenced by extraversion and openness in their readiness to accept change.

From the analysis, the hypothesis that predicted that gender would influence acceptance of change, that is male would score low on acceptance of change scale than females was accepted. It was observed that females scored higher than males. This confirmed and supported previous findings on attitude toward change that showed that males are reluctant to change than females (Gilmore, Shea \& Useem, 1997). This may partly be due to the fact that male employees constitute a large percentage of organization's workforce and to a large extent contribute to and determine policies and practices in organizations. Essentially, they may endeavour to sustain such practices especially if they thrive within bureaucratic setting. This suggest that change process as highlighted by organizational change might not be a complete transition for some employees especially males. Since positive attitudes to change were found to be vital in achieving organizational goals and in succeeding in change programmes (Eby et. al., 2000; Kotter, 1996; Gilmore and Barnett, 1992) 
organisations have to focus attention on individual differences in addressing negative attitude to change (King and Anderson, 1995).

On other hand demographic variables considered in the study for the male employees did not show any significant contribution to the acceptance of change jointly and independently except for salary. It shows that men were ready to accept change provided that self competence is available and the salary attached to the change is good enough. As a man/worker, it is suspected, especially in this culture, because the man is the "breadwinner" of the house, any opportunity to experience an increase in the salary is welcomed. For the females however, though there was significant joint contribution of the demographic factors considered, it was only age that had independent contribution to acceptance of change among the female employees. Why was age a significant factor? Could they be thinking of old age and nowhere to go if they are removed from work as a result of change? If the argument is acceptable then it might be of interest to look at cadre of employees against gender on acceptance of change.

Tables 6 and 7 showed the results of this expectation, where it was observed that a significant relationship exists between job cadre and gender acceptance of organizational change. It was observed that the higher you are on the organizational ladder, whether you are female or male the more you are likely to accept organizational change. Since change is widely accepted as almost always top-down and induced by the management and resistance to change perceived by management to stem from non-management members acceptance is expected from them (Cheng \& Petrovic-Lazarevic, 2004; Coghlan, 1993). In addition, it was discovered that males were more predisposed towards acceptance as revealed by the mean score. This might have to do with the perceived self competence of the males that they could cope with whatever change that is coming as discussed earlier. Organizations keep changing, and this is not likely to stop, so when joining the workforce and moving up in an organization, it is that ability to continue to embrace change, learn and grow that will ensure your ability to flex, adapt and lead."

\section{Limitation}

The major limitation of this study was in the fact that the interaction between gender and other factors was not examined. The study would have been more beneficial to the management of the federal civil service if, for example, status/cadre by gender interaction were examined so that policies could be initiated in this direction. However, this was not the focus of the present study.

\section{References}

Adeniji, A.A., Osibanjo, O.A. and Abiodun, A.J. 2013. Organisational Change and Human Resource Management Interventions: An Investigation of the Nigerian Banking Industry. Serbian Journal of Management. 8(2): 2-16. 
Armenakis, A.A., Harris, S.G. \& Mossholder, K.W. 1993. Creating readiness for Organizational change. Human Relations. 46: 681-703.

Armenakis, A.A. \& Arthur, G.B. 1999. Organizational Change: A Review of Theory and Research in the 1990s. Journal of Management. 25(3): 293315.

Ashford, S.J. 1988. Individual Strategies for Coping with Stress during Organizational Transitions. Journal of Applied Behavioural Science. 24.

Babakus, E., Cravens, D.W., Johnston, M. \& Moncrief, W.C. 1996. Examining the role of organizational variables in the sales person job satisfaction model. The Journal of Personal Selling and Sales Management. 16: 33-46.

Bingham, L.B. \& Charles, R.W. 1996. The Administrative Dispute Resolution Act of 1990: How do We Evaluate Its Success? Journal of Public Administration Research and Theory. 6(3): 383-411.

Carnall, C.A. 1986. Toward a Theory for the Evaluation of Organizational Change. Human Relations Journal.

Callan, V.J. 1993. Individual and Organizational Strategy for Coping with Organizational Change. Work \& Stress. 7: 63-75.

Cheng, S.L. \& Petrovic-Lazarevic, S. 2005. Resistance to Change. Monash Business Review. 1(1): 40-43.

Coch, L. \& French, J. 1948. Overcoming Resistance to Change Human Relations. 1(4): 512-32.

Cordery, J., Bartol, K.M., Mueller, W. \& Parker, S. 1991. Multiskilling: the view of public sector human resources managers. Asia Pacific Human Resources Management. 55: 225-41.

Eby, Lilian T., Adams, Danielle M., Russel, Joyce, E.A. \& Gaby, Stephen H. 2000. Perceptions of organizational readiness: factor related to employees' reactions to the implementation of team based selling. Human Relation. 53: 419-442.

Eisenberger, R., Huntington, R., Hutchison, S. \& Sowa, D. 1986. Perceived Organizational Support. Journal of Applied Psychology. 71: 500-507.

Evans, P., Pucik, V., Barsoux, J.L. 2002.. The Global Challenge - Frameworks for International Human Resource Management. International Edition. McGraw Hill.

Gagné, M., Koestner, R. \& Zuckerman, M. 2000. Facilitating Acceptance of Organizational Change: The Importance of Self-Determination. Journal of Applied and Social Psychology. 30(9): 1843-1852.

Gardner, D.G., Dunham, R.B., Cummings, L.L. \& Pierre, J.L. 1987. Employee Focus of Attention and Reactions to Organization Change. Journal of Applied Behavioural Science. 23(3): 351-70.

Gilmore, T. and Barnett, C. 1992. Designing the social architecture of participation in large groups to effect organizational change. The Journal of Applied Behavioral Science. 28: 534-548. 
Gilmore, T., Shea, G. and Useem, M. 1997. Side effects of corporate culture Transformations. Journal of Applied Behavioral Science. 33: 174-189.

Glaser, S.R., Zamanou, S. \& Harker, K. 1987. Measuring and Interpreting Organisational Culture. Management Communication Quarterly. I(2): 133148.

Cohglan, D. 1993. A person centered approach to dealing with resistance to change. Leadership and Organisation Development Journal. 14(4): 104.

Gosling, S.D., Rentfrow, P.J. \& Swann, W.B. 2003. A very brief measure of the Big-Five personality domains. Journal of Research in Personality. 3(6): 504-528.

Greenhalgh, L. \& Rosenblatt, Z. 1984. Job Insecurity: Toward Conceptual Clarity. Academy of Management Review. 9: 438-448.

Holbeche, L. 2006. Understanding Change: Theory, Implementation and Success. Oxford, UK: Roffey Park Management Institute, ButterworthHeineman.

Huse, E.F. 1980. Organizational Development and Change. $2^{\text {nd }}$ edition. St. Paul MN: West.

Iverson, R.D. 1996. Employee acceptance of Organizational change: the role of Organizational commitment. The International Journal of Human Resources Management. 7: 122-49.

Jimmieson, N.L., Terry, D.J., Callan, V.J. 2004. A Longitudinal Study of Employee Adaptation to Organizational Change: The Role of ChangeRelated Information and Change-Related Self Efficacy. Journal of Occupational Health Psychology. 9(1).

Johlke, M.C., Stamper, C.L., Shoemaker, M.E. 2001. Antecedents to Boundary-Spanner Perceived Organizational Support. Journal of Managerial Psychology. 17: 116-128.

Judson, A.S. 1991. Changing Behavior in Organizations: Minimizing Resistance to Change. Cambridge, MA: Blackwell.

Kotter, J.P. 1995. Leading Change: Why Transformation Efforts Fail, Harvard Business Review. 73(2): 59-67.

Kotter, J.P. 1996). Leading Change. Watertown, MA: Harvard Business School Press.

Laurent, A. 2003. Entrepreneurial Government: Bureaucrats as Business People. In New Ways of Doing Business. In Mark A. Abramson and Ann M. Kieffaber (eds.). Lanham, MD: Rowman \& Littlefield. 13-47.

Lewin, K. 1947. Group Decision and Social Change. Readings in Social Psychology. In Newcomb, T.M. and Hartley, E.L. (eds.). New York: H. Holt, Rinehart and Winston. 340-344.

McCrae, R.R. \& Costa, P.T. 1986. Personality, coping, and coping effectiveness in an adult sample. Journal of Personality. 54: 385-405.

McHugh, M. 1997. The stress factor: another item for the change management agenda? Journal of Organizational Change Management. 10(4): 345-62.

Mullins, L.J. 2010. Management and Organizational Behaviour. Ninth Edition. England: Pearson Education Limited. 
Nadler, A. \& Nadler, M.B. 1998. Champion Of Change: How CEOs and Their Companies are Mastering the Skills of Radical Change. San Francisco: Jossey-Bass.

Olaopa, T. 2009. Public Administration and Civil Service Reforms in Nigeria. Ibadan: University Press PLC.

Olufemi, J.A. 2009. Managing Organisational Change in Nigeria Manufacturing Enterprises: Lessons from the Unilever Nigeria Plc. International Business Management. 3(2): 15-21.

Osaghae, E. 1995. The study of political transitions in Africa. Review of African Political Economy. June 22.

Pettigrew, A.M. 1979. On Studying Organizational culture. Administrative Sciences Quarterly. 24: 570-581.

Tafarodi, R.W. \& Swann, Jr. W.B. 1995. Self-Linking and Self-Competence as Dimensions of Global Self-Esteem: Initial Validation of a Measure. Journal of Personality Assessment. 65(2): 322-342.

Schein, E.H. 1979. Personal Change Through Interpersonal Relationship. In Bennis, W., Van Maanen, J., Schein, E. and Steele, F. (eds.). Essays in Interpersonal Dynamics. Homewood, IL: The Dorsey Press.

Schein, E.H. 1992. Organizational Culture and Leadership. $2^{\text {nd }}$ edition. San Francisco, CA: Jossy-Bass.

Shaw, J.B., Fields, M.W., Thacker, J.W. \& Fisher, C.D. 1993. The Availability of Personal and External Coping Resources: Their Impact on Job Stress and Employee Attitudes during Organizational Restructuring. Work \& Stress. 7: 229-246.

Spector, P.E. 1982. Behaviour in Organization as a Function of Employee's Locus of Control. Psychology Bulletin.

Terry, D.J. \& Callan, V.J. 2000. Employee adjustment to an organizational change: A stress and coping Perspective. In P. Dewe, M. Leiter \& T. Cox (eds.). Coping, Health, and Organizations. Taylor \& Francis. 259-276.

Vakola, M., Tsaousis, I. \& Nikolaou, I. 2003. The role of emotional intelligence on employees' attitudes towards organisational change. $9^{\text {th }}$ Panhellenic Conference of Psychological Research, Rhodes, Greece.

Vakola, M., Tsaosis, I. \& Nikolaou, I. 2004. The role of emotional intelligence and personality variables on attitudes toward Organizational change. Journal of Managerial Psychology. 19(2): 88-110.

Vakola, M. \& Nikolaou, I. 2006. Exploring Individual Readiness to Organizational Change. Annual Meeting of the Academy of Management, Atlanta, USA.

Young, G.J. 2001. Transforming the Veterans Health Administration: The Revitalization of VHA. Transforming Organization. In Mark. A. Abramson and Paul R. Lawrence, Lanham(eds.). MD: Rowman \& Littlefield.139-172. 
The Nigerian Journal of Sociology and Anthropology Vol. 12 no. 2

Zamanou, S.G. \& Kenneth, H. 1987. Measuring and Interpreting Organizational Culture. Management Communication Quarterly. 1(2): 173-198. 